\title{
OBJETOS DE APRENDIZAGEM APLICADOS AO ENSINO DA NANOCIÊNCIA
}

\author{
Camila Bezerra Silva ${ }^{1}$, Nádia Ferreira de Andrade ${ }^{2}$, \\ FELIPE MOREIRA BARBOZA ${ }^{2}$ \\ ${ }^{1}$ Instituto Federal de Educação, Ciência e Tecnologia do Ceará, Campus de Ubajara \\ ${ }^{2}$ Instituto Federal de Educação, Ciência e Tecnologia do Ceará, Campus de Tianguá \\ <camilabsa111@gmail.com>. <nadiafisica@gmail.com> \\ $<$ felipembarboza@hotmail.com>
}

DOI: $10.21439 /$ conexoes.v10i4.951

\begin{abstract}
Resumo. Tendo em vista os avanços tecnológicos a que temos tido acesso nos últimos anos, este trabalho se destaca pela importância de se abordar, no âmbito escolar, assuntos atuais de nanociência com foco na utilização de "Objetos de Aprendizagem" (OA's). Essa proposta tem como principal objetivo possibilitar recursos e opções ao funcionamento desses instrumentos aplicados ao ensino. Foi realizada uma pesquisa de campo, por meio de um questionário, com os professores de Física das escolas estaduais de Tianguá - CE, localizadas na zona urbana da cidade, são elas: Escola de Ensino Médio Tancredo Nunes de Menezes, Escola de Ensino Médio Monsenhor Aguiar, Liceu de Tianguá José Ni Moreira e a Escola Estadual de Educação Profissional Professor Sebastião Vasconcelos Sobrinho. Foi sondado o ensino da nanociência no nível médio nestas instituições e a utilização dos objetos de aprendizagem no auxílio da explicação destes conceitos. Na pesquisa ficou nítido que muitos professores têm conhecimento da nanociência, mas não mostram esses conceitos na sala de aula, porém consideram importante que os alunos obtenham tais informações, mesmo que de forma rápida. Ao descrever os OA's percebemos que estes são de fácil manipulação e nos possibilitam uma compreensão bem significativa dos conceitos envolvidos na nanociência, representado em uma linguagem acessível para o professor/aluno de nível médio. Foi proposta neste trabalho uma nova perspectiva para o ensino da nanociência, considerando a importância dos alunos compreenderem estes assuntos modernos que estão tomando uma difusão cada vez maior na mídia e na indústria.
\end{abstract}

Palavras-chaves: Ensino médio. Nanociência. Objetos de Aprendizagem.

\begin{abstract}
Given the technological advances that have had access in recent years, this study highlights the importance of addressing, in schools, current affairs nanoscience focusing on the use of "learning objects" (OA's). This proposal aims to enable features and options for the operation of these instruments applied to the teaching of science. A field survey was conducted through a questionnaire, with the physics teachers of state schools in Tianguá - EC, located in the urban area, they are: High School Tancredo Nunes de Menezes, High School Monsignor Aguiar, School Tianguá Liceu Ni Jose Moreira and the State School of Vocational Teacher SebastiãoVasconcelos Sobrinho. It was probed nanoscience teaching in secondary education in these institutions and the use of learning objects in helping to explain these concepts. In the research it became clear that many teachers have knowledge of nanoscience, but do not show these concepts in the classroom, but consider important for students to obtain such information, even if quickly. Describing the OA's realize that these are easy to handle and allow a very significant understanding of the concepts involved in nanoscience, represented in a language accessible to the teacher / middle level student. It was proposed in this paper a new perspective to the teaching of nanoscience, considering the importance of the students understand these modern subjects which are taking an increasing diffusion in the media and industry.
\end{abstract}

Keywords: Highschool. Nanoscience. Learning Objects. 


\section{INTRODUÇÃO}

A Nanociência é uma área de pesquisa bastante inovadora e considerada recente quando comparada a outras áreas de estudo. Este campo de atuação vem ocupando grande espaço em diversos meios midiáticos como: internet, televisão, revistas, palestras, cursos, livros, entre outros. Por ser um tema moderno e que apresenta uma rápida difusão, muitos professores e pesquisadores apostam na nanociência como uma área promissora para a produção de novos produtos, como por exemplo: meias anti-odor, tecidos impermeáveis, preservativos, filtros solares, creme dental, curativos, tintas resistentes a riscos, cosméticos contra o envelhecimento, dispositivos tecnológicos, dentre outras invenções (ALVES, 2010).

A nanociência estuda fenômenos que ocorrem na escala nanométrica, uma escala que corresponde à ordem de tamanho de $10^{-9} \mathrm{~m}$. Trabalhar nesta escala possibilita a manipulação e a organização de átomos e moléculas, o que pode ser aplicado ao desenvolvimento de novos produtos e tecnologias avançadas. Esta "nanomanipulação" possibilita vasta aplicabilidade na medicina, agricultura, fármacos, equipamentos tecnológicos, produtos estéticos, esportivos, etc. (INVERNIZZI 2008).

O marco para o estudo da nanociência deu-se em 1959, em uma palestra, "Há muito espaço lá embaixo", o físico norte americano Richard Feynman sugeriu a possibilidade de colocarmos os 24 volumes da enciclopédia britânica na ponta de um alfinete (FEYNMAN, 2004). Com esta afirmativa, Feynman foi bastante audacioso, o que resultou em várias indagações de como seria possível tamanha proeza. Ele estava sugerindo a possibilidade de estudar e criar materiais através da manipulação de átomos e preencher espaços em nível atômico, jamais vistos até então a olho nu. Esta é a principal proposta da nanociência e nanotecnologia.

Um dos pontos que caracteriza e diferencia os materiais em escala nano é o fato de eles apresentarem um aumento da área superficial mantendo o seu volume constante, proporcionando assim uma maior área de contato, reação e eficiência do produto. Muitos compostos, quando produzidos em escala nano, podem ter suas propriedades potencializadas e distintas quando comparadas às suas características em escala macroscópica. Este fato permite a produção de equipamentos mais compactos e modernos (ELLWANGER et al. 2012).

A economia mundial deposita anualmente investimentos milionários em estudos voltados para a nanociência (FERREIRA; RANGEL, 2009). Estes investimentos resultam em avanços tecnológicos que visam, por exemplo, melhorias na saúde e na qualidade de vida das pessoas. No Brasil, muitas Universidades e centros de pesquisa se empenham bastante no desenvolvimento e no estudo desta área, tendo como um dos principais objetivos a busca pelo aprimoramento de técnicas na tentativa de descobrir novos materiais nanoestruturados.

No âmbito do ensino, a nanociência permite a interdisciplinaridade, envolvendo as áreas das Ciências da Natureza e Matemática. É comum encontrarmos divulgações midiáticas com o prefixo "nano" em diversos veículos de comunicação. Deste fato surge então a necessidade de migrarmos estes conceitos de tecnologias e pesquisas envolvendo essa linha de estudo para o ambiente escolar, pois "o aprendizado de Física deve estimular os jovens a acompanhar as notícias científicas, orientando-os para a identificação sobre o assunto que está sendo tratado e promovendo meios para a interpretação de seus significados" (BRASIL, 2000, p. 27).

Entende-se que o estudante deve compreender o que caracteriza estas novas pesquisas e o que as diferencia das demais. Além disso, temas envolvendo o "nano" são bem instigantes e podem ser utilizados na tentativa de despertar a curiosidade dos alunos em nível de ensino médio.

Para inserir os conceitos da nanociência nas escolas, bem como outros temas, é necessário que os professores preparem suas aulas buscando métodos mais atrativos, diferentes do tradicional, para que os alunos sintam prazer em aprender, se envolvam com a aula apresentada e, consequentemente, absorvam mais conhecimento. Dentre estes métodos, podemos citar: experimentos, gincanas, objetos de aprendizagem, brincadeiras, jogos, dinâmicas, objetos representativos, informações inovadoras, etc. Preparar aulas mais atraentes é um trabalho árduo, mas utilizar-se de metodologias diferentes no ambiente escolar é, talvez, o caminho mais acessível que pode resultar na melhoria do rendimento escolar dos alunos (SILVA; BARBOZA, 2014).

Uma das formas mais viáveis de se inserir conceitos de nanociência no ensino médio é a utilização de objetos de aprendizagem (OA's) (ELLWANGER et al. 2012), que "são recursos digitais dinâmicos, interativos e reutilizáveis em diferentes ambientes de aprendizagem, elaborados a partir de uma base tecnológica", de acordo com Audino e Nascimento (AUDINO; NASCIMENTO, 2010, p. 141). Estes recursos, como: animações digitais, imagens, simulações computacionais, vídeos, etc., facilitam o entendimento por parte do educando, pois, os "objetos virtuais de aprendizagem podem contribuir de forma significativa na melhoria da aprendizagem de nossos alunos" (AMARAL; 
OBJETOS DE APRENDIZAGEM APLICADOS AO ENSINO DA NANOCIÊNCIA

SANTOS, 2012, p. 1).

Esta ferramenta de ensino não deve, no entanto, ter o propósito de substituir as aulas, mas deve ser utilizada como método didático para auxiliar o docente na abordagem do conteúdo. A partir da importância dessa temática, destaca-se a utilização dos OA's para a complementação do aprendizado do aluno no ensino da Física. Estes recursos podem ser utilizados como meios facilitadores do ensino/aprendizagem, de forma que o conteúdo abordado em sala de aula seja o mais didático possível para os estudantes.

Os OA's podem facilitar a transmissão de alguns conteúdos que teoricamente seriam bem mais complexos de se compreender e até mesmo de se explicar, pois quando os conteúdos de Física são repassados de forma habitual, ocorre uma grande dificuldade em vincular a atenção dos estudantes à aula ministrada (SALES et al. 2008). Muitas vezes estes estudantes não conseguem relacionar os conteúdos teóricos com os acontecimentos cotidianos. Como consequência eles não conseguem interagir ativamente, o que faz com que estes permaneçam na sala de aula como meros expectadores. Devido a falta de reciprocidade entre o aluno e o professor, o educador não tem êxito com os objetivos traçados, tornando as aulas muitas vezes exaustivas.

O principal objetivo deste trabalho é apresentar recursos e opções de funcionamento de alguns objetos de aprendizagem voltados à nanociência, descrevendo-os detalhadamente e mostrando a importância de se compreender estes assuntos atuais. Dessa forma, iremos apresentar dados de uma pesquisa, realizada por meio de um questionário diagnóstico, sondando o ensino de nanociência com foco na utilização dos OA's, com nove professores de Física das escolas estaduais de Tianguá - CE, localizadas na zona urbana da cidade, são elas: Escola de Ensino Médio Tancredo Nunes de Menezes, Escola de Ensino Médio Monsenhor Aguiar, Liceu de Tianguá José Ni Moreira e a Escola Estadual de Educação Profissional Professor Sebastião Vasconcelos Sobrinho.

\section{OBJETOS DE APRENDIZAGEM E O EN- SINO DA FÍSICA}

A Física, como uma ciência que estuda e explica os fenômenos naturais, permite ao educador uma grande variedade de metodologias de ensino. Seu campo de atuação não possui limites definidos e as pesquisas nesta área são frequentes, sendo algumas traduzidas por meio do desenvolvimento tecnológico. Ela está presente em nosso dia a dia, esclarecendo desde as indagações mais bucólicas até as mais intricadas. No âmbito escolar, nos permite uma parceria eficaz entre teoria e prática, tornando o processo de aprendizagem mais significativo. Segundo Pelizzari:

$\mathrm{O}$ aluno que hoje frequenta uma escola infelizmente ainda vê o conhecimento como algo muito distante da sua realidade, pouco aproveitável ou significativo nas suas necessidades cotidianas. Na sua teoria, Ausubel apresenta uma aprendizagem que tenha como ambiente uma comunicação eficaz, respeite e conduza o aluno a imaginar-se como parte integrante desse novo conhecimento através de elos, de termos familiares a ele. (PELIZZARI et al. 2002, p. 41)

Dessa forma, é de suma importância para o educador direcionar formas para melhorar o processo de ensino/aprendizagem, de maneira que o aluno possa ter um ambiente mais motivador, aprazível e como decorrência, obtenha mais conhecimento sobre o conteúdo exposto. Compreendemos que "na era da tecnologia, da informação e da conectividade às redes sociais, a sala de aula goza de um anacronismo imutável e, assim permanece desalinhada do mundo vivencial do aluno" (SALES; LEITE; VASCONCELOS, 2015, p.1).

Certas disciplinas permitem que o professor seja mais flexível, no sentido de não permanecer fincado em aulas unicamente teóricas com métodos retrógrados, cravados em um tradicionalismo imutável, aulas embasadas em instrumentos tradicionais, como apenas pincel, lousa, apagador e livro didático.

$\mathrm{O}$ aluno tem a necessidade de ludicidade na sala de aula. Métodos tradicionais resultam na rotulação da Física como uma disciplina de difícil compreensão e meramente matemática. De acordo com os Parâmetros Curriculares Nacionais (2000, p.23): “... é imprescindível considerar o mundo vivencial dos alunos, sua realidade próxima ou distante, os objetos e fenômenos com que efetivamente lidam ou os problemas e indagações que movem sua curiosidade". Então, se faz necessário proporcionar ao aluno um ambiente mais planejado, mostrando que é possível aprender "brincando". Contudo, "Compreendemos que ensinar não é uma tarefa fácil, ou seja, não existem soluções simples ou únicas, nem métodos prontos que possibilitem o bom aprendizado" (SILVA; BARBOZA, 2015, p. 7).

Quando os experimentos e instrumentos de aprendizagem já não são acessíveis, têm-se como opção os OA's que são utilizados com fins educativos para o melhoramento do processo de ensino/aprendizagem. Além disso, a utilização dos objetos de aprendizagem no contexto aqui inserido envolve uma base tecnológica com propósito de proporcionar uma interatividade ao ambiente escolar, pois "a aprendizagem significativa e o uso da tecnologia estão inter-relacionadas e são interativas e interdependentes" (FLÔRES; TAROUCO, 2008, p. 2). 
OBJETOS DE APRENDIZAGEM APLICADOS AO ENSINO DA NANOCIÊNCIA

Entre os tipos de OA's temos, por exemplo: imagens - representação visual imóvel; animações digitais - que criam movimentos em imagens tendo por base a tecnologia, sendo que o observador pode interagir com a mesma; simulações - imitam um fenômeno e processo do mundo real através de animações; áudios - transmissor e reprodutor sonoro; mapas conceituais - ferramenta de cunho tecnológico ou não que organiza o conhecimento, conectando palavras para dar sentido a um contexto estudado; textos - representação de ideias escritas por meio de palavras; vídeos - representa a sucessão de imagens dando movimento ininterrupto a uma representação; jogos interativos - atividade em que se brinca interagindo com um ambiente, partindo de regras e cujo principal objetivo é vencer; gráficos - esquematização gráfica de informações organizadas para melhorar a compreensão de um processo; tabelas - representação visual de dados organizados por linhas e colunas, entre outros.

"Entretanto, nenhum recurso pedagógico, por si só, será suficiente, uma vez que é necessário o engajamento por parte dos outros atores do cenário pedagógico, visando transformar a sala de aula em um espaço mais motivador" (SALES et al., 2008, p. 11).

O educando, seja em qual modalidade de ensino estiver inserido, apresenta a necessidade de compreender as pesquisas atuais que estamos vivenciando para, quem sabe, de acordo com sua aceitação, influenciar na sua escolha profissional (HEALY, 2009).

É importante que os alunos de ensino médio saibam identificar o que caracteriza algumas inovações, mas infelizmente o núcleo escolar prioriza os conteúdos que são mais cobrados em provas externas, como nos vestibulares e no Exame Nacional do Ensino Médio (Enem). Esta metodologia visa um maior número de acertos e a obtenção de uma pontuação mais elevada, tornando o ensino fragmentado e muitas vezes priorizando status para a instituição de ensino.

\section{A Ciência é um corpo de informações dinâmicas e que evolui com o tempo, em interação com outras linhas do saber, a Sociedade e o Ambiente. "Entretanto, tais traços pouco têm emergido, em geral, nas práticas de ensino de Física na escola de nível médio." (MACHADO; NARDI. 2006 p. 47).}

Dessa forma, inserir conceitos inovadores de nanociência na escola ainda não é uma realidade homologada.

(...) sabe-se que a compreensão dos processos e conceitos envolvidos em dispositivos em escala nanométrica é compartilhada por poucos, visto que em muitos casos são conhecimentos abstratos e são necessárias ferramentas matemáticas sofisticadas, impedindo ao público leigo participar das discussões e relativizar possíveis implicações (ELLWANGER et al. 2012 p. 2).
Por ser uma área de pesquisa que atinge uma recente difusão, o acervo de instrumentos educativos para explicar as propriedades e características da nanociência ainda é ínfimo. Podemos citar como uma das principais fontes de pesquisa para encontrar objetos de aprendizagem voltados a essa área, o espaço virtual "MAIS UNIFRA" (UNIFRA, 2011).

Estes objetos são de fácil manipulação e nos possibilitam uma compreensão bem significativa dos conceitos envolvidos pela nanociência, sendo eles representados em uma linguagem acessível para o público de nível médio, pois a escala nanométrica por não ser vista a olho nu dificulta o entendimento dessa ciência por meio dos alunos e professores.

$\mathrm{Na}$ pesquisa realizada com os professores foram destacados os objetos de aprendizagem: simulações, vídeos, animações e imagens. Estes apresentam na internet um acervo considerável em relação a outros tipos de OA's e são ferramentas utilizadas pelo professor em sala de aula para explicar conceitos diversos. A seguir descreveremos detalhadamente estes instrumentos aplicados ao ensino de nano, mostrando riqueza de conhecimento que cada um deles pode nos oferecer.

\subsection{DESCRIÇÕES DETALHADAS DE ALGUNS OA'S APLICADOS AO ENSINO DA NANOCIÊN- CIA}

\subsubsection{ANIMAÇÃO}

A animação digital é uma entidade tecnológica em que as imagens ou outras ferramentas são organizadas para gerar a produção de movimento. O manipulador pode interagir ativamente com o instrumento educacional, comandando a atividade conforme a sua necessidade.

A seguir serão discutidas duas animações digitais encontradas no site MAIS UNIFRA 1 (MAIS UNIFRA, 2015), que podem ser direcionadas para uma aula introdutória aos conceitos de nanociência.

A Figura 1 representa a animação onde se verifica a diminuição da escala de alguns elementos, partindo da grandeza macroscópica até o nível atômico. Para visualizar toda a tabela é necessário mover o cursor para baixo. Para aumentar a ilustração das imagens basta clicar em cima dos rótulos amarelos dos elementos. Inicialmente, observa-se na escala macroscópica o corpo humano, passam-se 15 ilustrações para então chegarmos à escala nanométrica, sendo esta representada pelo diâmetro do fulereno e a espessura do grafeno. A representação gráfica segue até a ilustração do núcleo atômico cuja ordem de grandeza é de $10^{-14} \mathrm{~m}$. Essa ani-

\footnotetext{
${ }^{1}$ Espaço virtual que contém objetos de aprendizagem destinados ao ensino de Nanociência, Letras, Química, Física e Matemática.
} 
mação é uma ilustração clara de quão pequena é a escala nanométrica, podendo ser utilizada ao se introduzir o estudo da nanociência, uma vez que os alunos terão dificuldade de imaginar o tamanho de algo nunca visto por eles e que fogem ao senso comum.

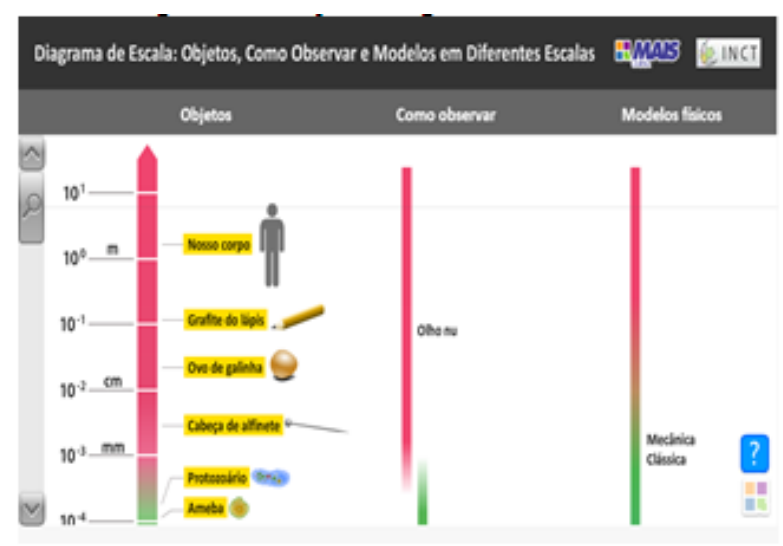

Figura 1: Objeto diagrama de escala Fonte: MAIS UNIFRA, 2015.

A Figura 2 representa uma animação onde se evidencia uma das características da nanociência, que é a possibilidade de aumentar a área superficial de um dado material deixando seu volume constante. Dessa forma, alcança-se uma reação mais rápida e efetiva e com a diminuição das peças obtêm-se dispositivos mais compactos e com melhor eficiência.

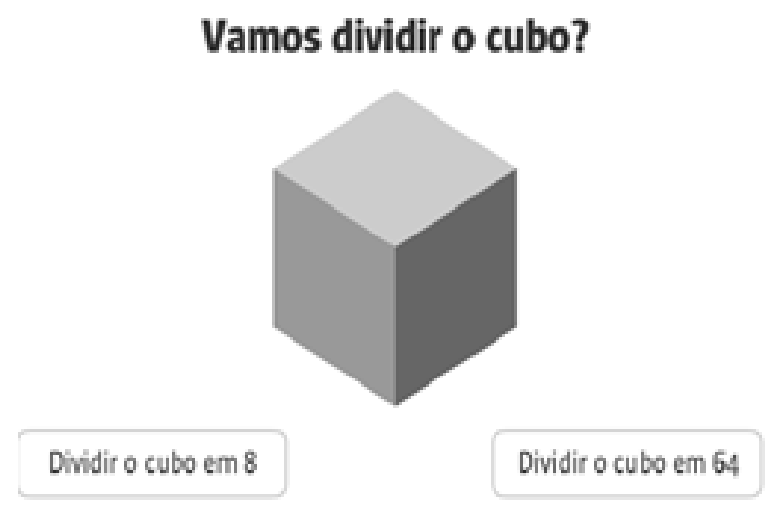

Figura 2: Objeto Área superficial Fonte: MAIS UNIFRA, 2015.

No início temos um cubo de tamanho considerável, a animação permite que você divida-o em oito ou em sessenta e quatro cubos menores. Percebe-se que o cubo inicial se divide em cubos menores, porém o volume é o mesmo, pois o cubo foi apenas fatiado e reorganizado em cubos menores sem acréscimo de volume. Contudo, aquele cubo tomou uma proporção maior do que o anterior, pois ele se multiplicou em vários outros cubos menores que alcançam um maior território de atuação e com suas propriedades preservadas.

\subsubsection{VÍDEO}

O vídeo também é um tipo de objeto de aprendizagem produzido através de uma sequência ininterrupta de imagens, é uma das ferramentas mais utilizadas no âmbito escolar, pois este possibilita uma compreensão eficaz de conhecimentos simples ou complexos. Sendo um instrumento ideal para trabalhar a nanociência, o vídeo permite uma clareza efetiva dos conceitos incógnitos e apreciados por parte de muitos, apresentando um dos mais amplos acervos em relação aos outros tipos de OA's.

Na Figura 3 foi representado um vídeo em que se observa a velocidade de reação de uma pastilha esfarelada e uma partícula inteira dentro de uma solução com água e um corante. A pastilha quando colocada inteira apresenta um tempo de reação mais longo, pois a área de contato dela é menor e consequentemente irá demorar mais para reagir com a solução do que a pastilha esfarelada. Esta é uma boa aproximação para representar uma das características da nanociência, de maior reação e miniaturização de materiais. Esse vídeo nos mostra que essa ciência também pode ser traduzida por meio de atividades simples e com materiais de fácil acesso.

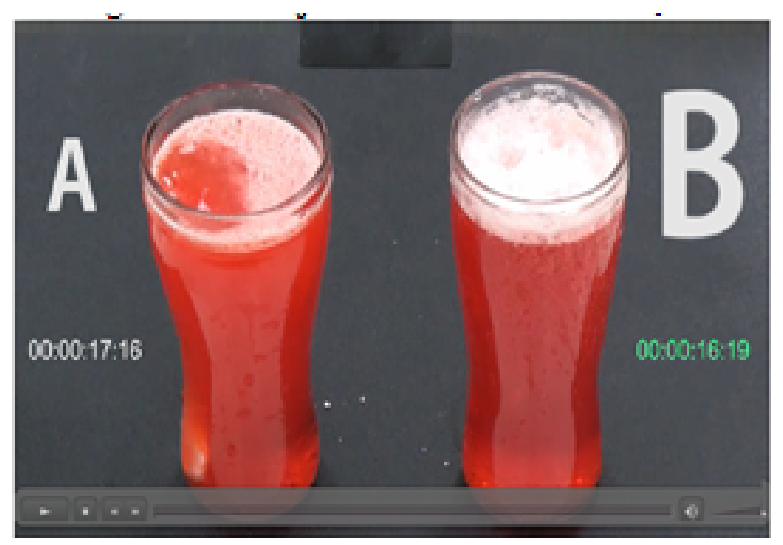

Figura 3: Objeto velocidade de reação Fonte: MAIS UNIFRA, 2015.

Essa ferramenta além de ser bem acessível e explicar essa propriedade de uma maneira bem simples, pode ser ilustrada por meio de um experimento de fácil ma- 
nuseio podendo migrar diretamente para a sala de aula com facilidade, tornando os conceitos sobre nanociência mais palpáveis.

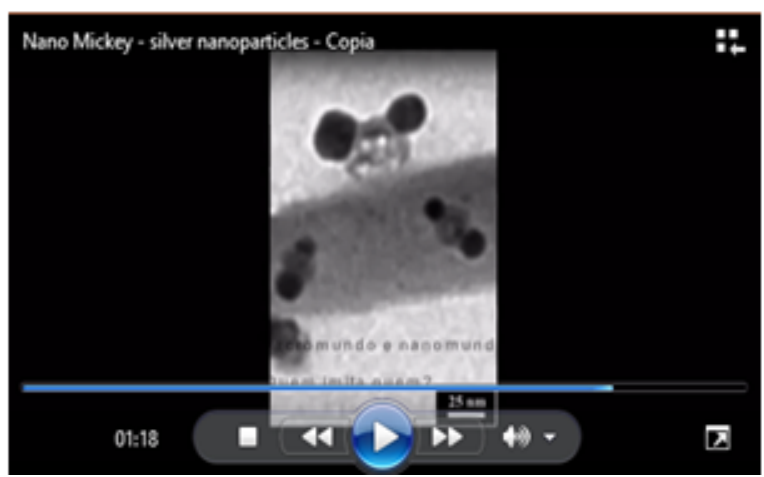

Figura 4: Objeto NanoMickey - silvernanoparticles Fonte: MAIS UNIFRA, 2015.

A Figura 4 ilustra um vídeo retirado do canal de vídeos, Laboratório de Química do Estado Sólido (LQES) Science (LQES Science, 2010). O vídeo trata de uma curiosa imagem que apareceu em um experimento realizado pelo grupo de pesquisa do professor Oswaldo Alves no Instituto de Química da Universidade Estadual de Campinas (Unicamp) que envolveu o aluno de doutorado Raphael Dias Holtz, financiado pela FAPESP. A imagem curiosa foi visualizada por meio de um Microscópio Eletrônico de Transmissão - MET (FAPESP 2010). O MET é um equipamento no qual uma amostra muito fina é atravessada por um feixe de elétrons que interagem com ela, formando uma imagem que é aumentada e detectada por um sensor como uma câmera CCD ou uma tela fluorescente em uma camada de filme fotográfico (CETENE, ).

A figura é resultado de um procedimento experimental onde foi preparado em uma autoclave nanofios de vanadato de prata $\left(\mathrm{AgVO}_{3}\right)$ decorados com nanopartículas de prata, que é uma nanoestrutura com ação antibacteriana quando incorporada a vários materiais como plásticos, tecidos e tintas (FAPESP, 2010). "Coincidência, acidente, acaso ou não, a verdade é que nano Mickeys estão lá e eles estão sorrindo", é assim que o professor Oswaldo Alves se refere à figura descrita (FAPESP, 2010).

Uma aproximação da imagem do nanofio revelou a figura do Mickey, personagem animado da Disney. $\mathrm{O}$ vídeo impressiona pela tamanha perfeição da semelhança e nitidez do Mickey. Esta imagem pode ser utilizada para explicar diversos conceitos de nanociência de uma forma bem curiosa, inusitada e significativa, além de gerar maior difusão, popularidade e questionamentos a respeito desse assunto. "A diferença é que a fama do Mickey pode contribuir para popularizar a nanotecnologia, especialmente entre as crianças", diz Alves (FAPESP, 2010). O vídeo finaliza com a indagação: macromundo e nanomundo...Quem imita quem?

\subsubsection{SIMULAÇÃO}

A simulação computacional é um dos tipos de OA's mais utilizados como ferramenta de ensino. Ela possibilita uma clareza bem efetiva de conceitos relacionados às mais diversas áreas de estudo. Estas "são recursos que simulam um sistema ou procedimento real onde permite que os alunos obtenham ou manipulem os dados daquela situação simulada" (SÁ; ALMEIDA; EICHLER, 2010, p. 4).

A Figura 5 representa a simulação computacional que mostra o tratamento do câncer por meio de nanotubos de carbono, que são alótropos do carbono com uma nanoestrutura cilíndrica. O prefixo "nano"vem do grego e significa "anão". Um nanômetro $(\mathrm{nm})$ equivale à bilionésima parte de um metro $\left(10^{-9} \mathrm{~m}\right)$. A página inicial do objeto mostra dois tipos de tratamentos: o fotoluminescente e o farmacológico, que podem futuramente ser utilizados para destruir as células cancerígenas.

No tratamento fotoluminescente os nanotubos de carbono são ejetados na veia por meio de uma seringa e eles percorrem o corpo até encontrar as células cancerígenas. Se os nanotubos de carbono absorvem um feixe de luz infravermelho haverá aquecimento das células, ocasionando assim a destruição das células cancerígenas.

No tratamento farmacológico os nanotubos também são ejetados na veia por meio de uma seringa e percorrem o corpo até encontrar as células cancerígenas. Eles servem como transportadores da medicação, proporcionando maior eficiência e diminuição dos efeitos colaterais uma vez que o tratamento é localizado.

A figura 6 representa uma simulação de um experimento realizado na Universidade Federal do Ceará (UFC) em colaboração com a Universidade de Campinas (Unicamp) (ANDRADE et al., 2015). Os pesquisadores observaram a reação de uma cadeia de carbono no interior de um nanotubo de carbono imerso em um meio com moléculas de água, este sistema por sua vez esteve submetido a determinados valores de pressão.

A simulação possibilita a visualização da estrutura interna, externa, frontal e lateral do nanotubo de carbono. Fica bem nítida a deformação do nanotubo e a vibração da cadeia de carbono quando ambos estão submetidos a uma dada pressão. Para um determinado valor de pressão, observa-se que a cadeia de carbono se liga quimicamente a um átomo de carbono do nanotubo, 
formando assim uma ligação química carbono-carbono.

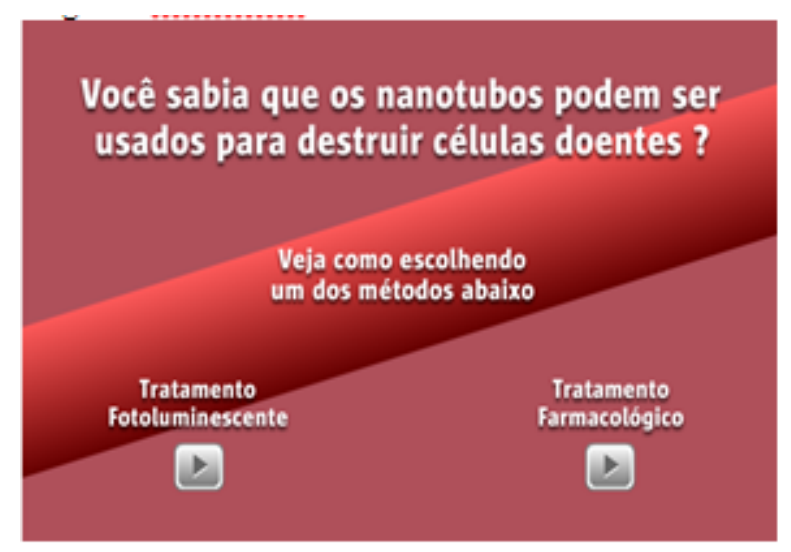

Figura 5: Nanotubos destruindo células cancerosas Fonte: MAIS UNIFRA, 2015.

\subsubsection{IMAGEM}

A imagem é uma representação visual imóvel, utilizada para ilustrar os mais diversos objetos, fenômenos, eventos, etc. É um objeto de aprendizagem muito utilizado nos livros e em aulas expositivas. Essa entidade torna claramente explícita o entendimento de alguns conceitos apresentados pelo professor. A "aprendizagem pode ser realizada por apenas um recurso, como uma imagem, ou ainda, usando vários recursos digitais combinados" (FLÔRES; TAROUCO, 2008, p. 9).

A Figura 7 representa uma imagem cujo autor é Thomas Warm Stock. Esta imagem mostra uma das propriedades da nanociência utilizadas na ornamentação das igrejas medievais.

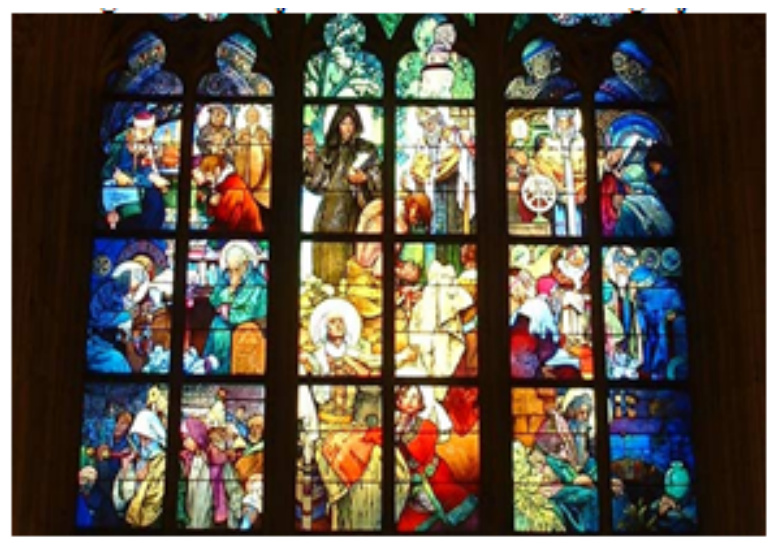

Figura 7: Objeto vitral colorido em igreja Fonte: MAIS UNIFRA, 2015.

Estes vitrais eram coloridos sem utilização de tintas, para atingir tal proeza o ouro era moído em tamanhos variados em escala nanométrica, em seguida este era diluído no vidro e com a incidência de um raio luminoso o vidro coloria-se de acordo com o tamanho das partículas de ouro presentes em cada região.

Como a luz branca é a composição de todas as cores, quando ela incide sobre o vidro, parte do raio luminoso refrata e parte reflete, pois ele se depara com um meio de índice de refração diferente. O raio refletido é o que chega aos nossos olhos trazendo a cor do objeto de acordo com o comprimento de onda e frequência do mesmo. Como o ouro nos vitrais está em diversos tamanhos nanométricos, seu índice de refração se altera, resultando na alteração do comprimento de onda e consequentemente na cor do objeto. Dessa forma, partículas nanométricas resultam num composto de cores, que 
só é obtido através de fenômenos de reflexão, refração e dispersão da luz.

A Figura 8 trata de uma representação da imagem em que se evidencia a super-resistência de tecidos feitos com nanotubos de carbono. Os nanotubos de carbono, que já foram mencionados anteriormente, são formados apenas por átomos de carbono, como o grafite e o diamante, apresentando um formato de cilindro com diâmetro na escala nanométrica.
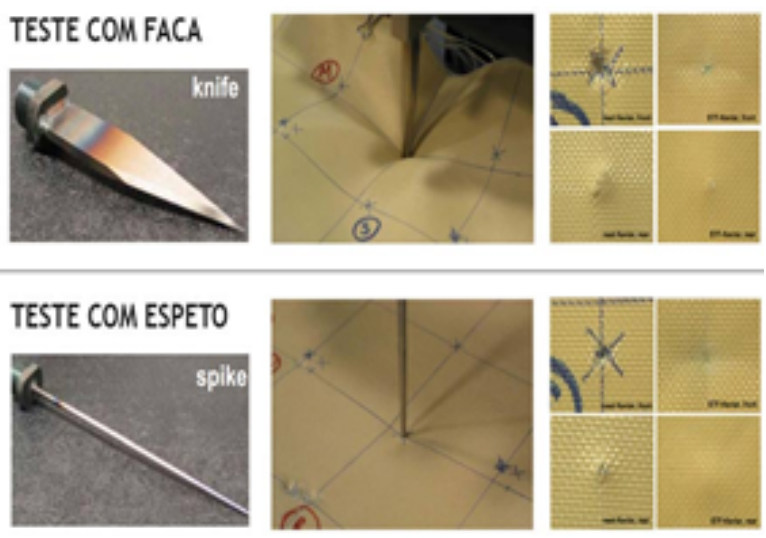

Figura 8: Objeto tecido super-resistente Fonte: MAIS UNIFRA, 2015.

Nos nanotubos, os átomos de carbono estão organizados de forma a apresentar propriedades jamais encontradas em outros materiais, apresentando extrema resistência, dureza, flexibilidade, alta condutividade elétrica e térmica, proporcionando uma vasta aplicação em produtos super-resistentes. Neste teste, o pano está sobre uma superfície flexível e faz-se uma perfuração no tecido com a faca e depois com um espeto, percebe-se que o tecido curva-se um pouco devido à flexibilidade da superfície abaixo do pano. Nota-se que tanto na parte superior quanto inferior o dano causado pelos instrumentos cortantes é muito pequeno. Essa é uma ilustração clara das aplicabilidades e benefícios que a nanotecnologia pode nos proporcionar.

\section{RESULTADOS E DISCUSSÕES}

A pesquisa foi realizada com nove professores de Física no município de Tianguá que conta atualmente com quatro escolas da rede estadual localizadas na zona urbana da cidade, que são elas: Escola de Ensino Médio Tancredo Nunes de Menezes, Escola de Ensino Médio Monsenhor Aguiar, Liceu de Tianguá José Ni Moreira e a Escola Estadual de Educação Profissional Professor Sebastião Vasconcelos Sobrinho.
Essas quatro escolas oferecem à comunidade cursos de ensino médio e apresentam um número pequeno de professores de Física, acarretando numa pesquisa com apenas nove docentes. A identificação destes não será divulgada por questões éticas. A pesquisa realizada foi do tipo questionário sendo este "um instrumento de coleta de dados constituído por uma série ordenada de perguntas que devem ser respondidas por escrito pelo informante, sem a presença do pesquisador" (GERHARDET; SILVEIRA, 2009 p. 67). Este questionário, aplicado como ferramenta de pesquisa, continha sete questões, sendo seis perguntas objetivas e uma subjetiva.

Inicialmente sondamos se os professores já tinham ouvido falar sobre nanociência, pergunta representada no gráfico 01 . As respostas foram bastante vantajosas, das quais aproximadamente $89 \%$ dos professores afirmaram que já ouviram falar em nanociência. Esse percentual significativo pode estar relacionado ao fato da nanociência estar atingindo um espaço considerável em meio às divulgações midiáticas. Apenas $11 \%$ apontaram que não tinham nenhum conhecimento sobre essa temática.

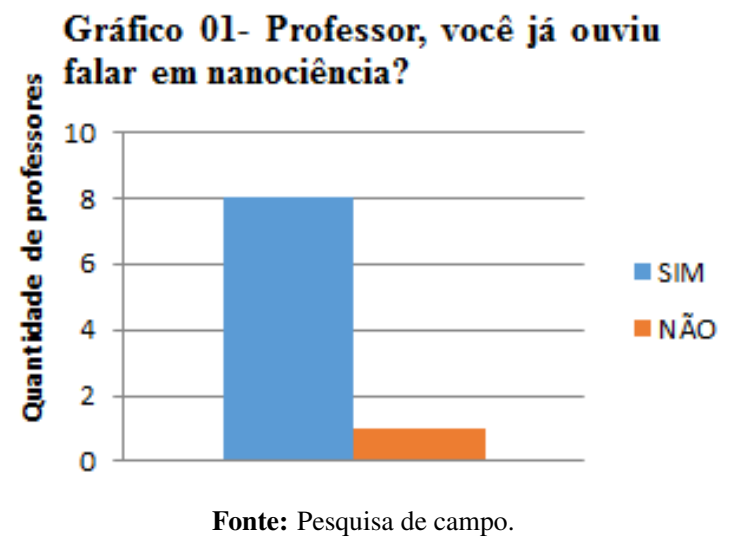

A pergunta 02 , representada pelo gráfico 02 , estava diretamente relacionada com a pergunta 01 , pois nela os docentes iriam apontar por quais meios obtiveram informação sobre nanociência. Os professores podiam marcar inúmeras alternativas, pois compreendemos que muitos são os meios midiáticos que divulgam essa ciência.

Se a resposta não estivesse entre as alternativas sugeridas, o professor poderia indicar por qual outro meio ele obteve essa informação marcando a alternativa "outros" e escrevendo qual outro meio no espaço destinado a isso. Apenas um educador apontou esta opção afirmando que obteve essa informação através de um artigo científico. Como resultado, foi obtido $39 \%$ por meio da internet; $11 \%$ pela televisão; $16,6 \%$ revistas; $16,6 \%$ por palestras e cursos; 11 por livros e 5,5\% outros (artigo). 


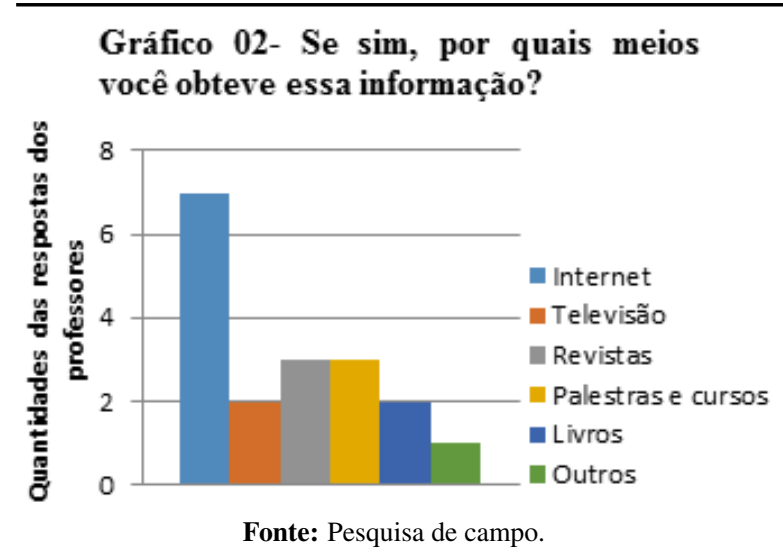

A maioria dos professores obtiveram informações sobre a nanociência por meio da internet, esse percentual pode estar ligado ao fato da internet ser um veículo de rápida e fácil acessibilidade para obtenção de informações. A menor porcentagem foi destinada para a opção "outros", em que o professor poderia indicar por qual meio ouviu falar em nanociência. Nela o professor obteve a informação por meio de artigos, esse pequeno percentual pode ter sido dado ao fato de que o uso de artigos necessita de uma pesquisa mais elaborada e um maior tempo de dedicação e estudo.

$\mathrm{Na}$ terceira pergunta, representada no gráfico 03 , indagamos se os conceitos de nanociência costumam ser abordados na escola. Das respostas 77,7\% dos participantes afirmaram que nunca migraram conceitos dessa ciência no âmbito escolar e 22,3\% responderam que sim. De acordo com a pesquisa, a minoria explicou conceitos de nanociência em sala de aula. Com isso, a maioria das respostas apontou que esses conceitos são pouco trabalhados no ambiente escolar. Entendemos que esse resultado esteja relacionado à problemática dos professores priorizarem os conteúdos existentes no currículo escolar ou ainda por ser uma ciência recente que necessita de uma aula mais elaborada e com tempo de preparação maior do que os conteúdos tradicionais que eles já estão acostumados a lecionar.

O gráfico 04 apresenta a resposta da quarta pergunta, segundo a qual os docentes deveriam responder se esse assunto poderia ser inserido, mesmo sendo de forma rápida, na grade curricular dos alunos de ensino médio.

Dos professores, $100 \%$ marcaram a alternativa sim. Nessa pergunta todos os professores apontaram que a nanociência pode ser inserida nas aulas de ensino médio. Fica evidente assim que estes a consideram uma ciência importante e que os alunos devem sim estar a par dos conceitos que a envolvem.

$\mathrm{O}$ gráfico 05 representa a quinta pergunta feita na

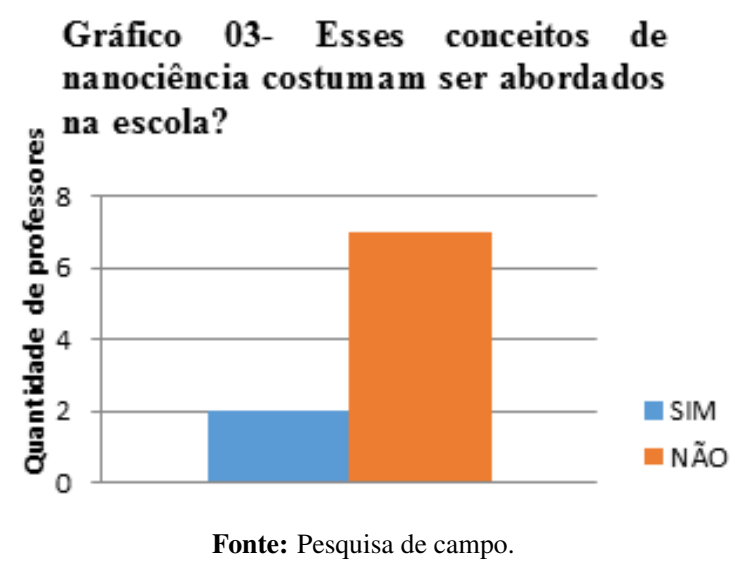

Gráfico 04- Você acha que esse assunto pode ser inserido, mesmo que seja abordado de forma rápida, na grade curricular dos alunos de ensino médio?

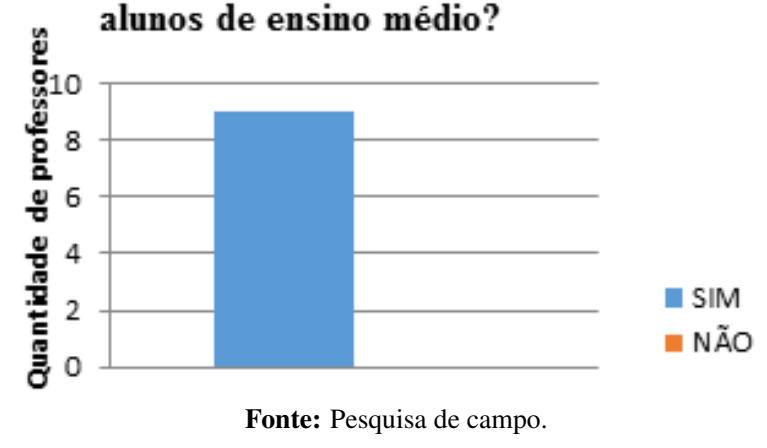


pesquisa, trata-se de um questionamento em que os docentes apontam se os alunos de ensino médio mostram interesse em compreender assuntos modernos, publicados pela mídia (noticiários, internet, etc.) que envolvem a nanociência. Destes educadores, aproximadamente $66,6 \%$ responderam que os alunos têm interesse, enquanto $22,2 \%$ responderam que não. O percentual restante, que equivale a um único docente, apontou que nunca teve a chance de abordar esse tema em sala de aula e este afirmou não saber como seria a aceitação dos alunos. O maior percentual das respostas dos professores foi a opção sim, o que sugere que os estudantes de ensino médio demonstram interesse em compreender pesquisas que abordem temas modernos.
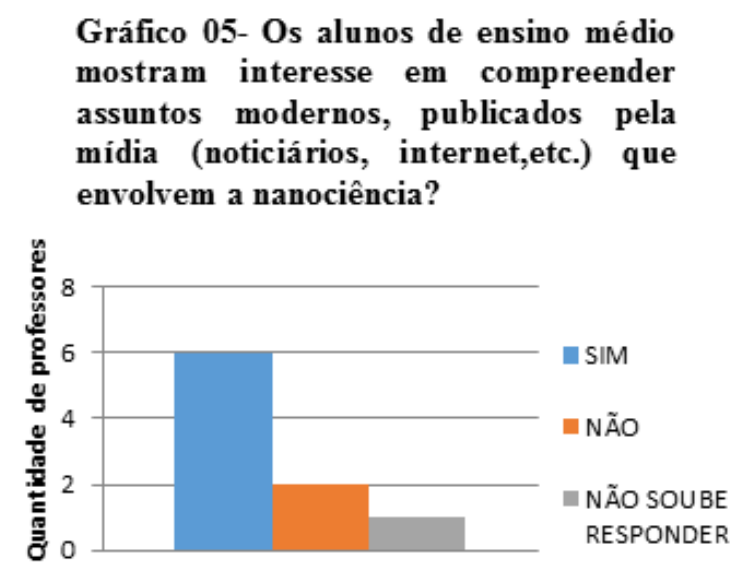

Fonte: Pesquisa de campo.

Representando a última questão objetiva do questionário temos o gráfico 06. Nessa pergunta fizemos uma conexão entre nanociência e os objetos de aprendizagem. Indagamos qual a melhor forma de transmitir esses conceitos para um aluno do ensino médio.

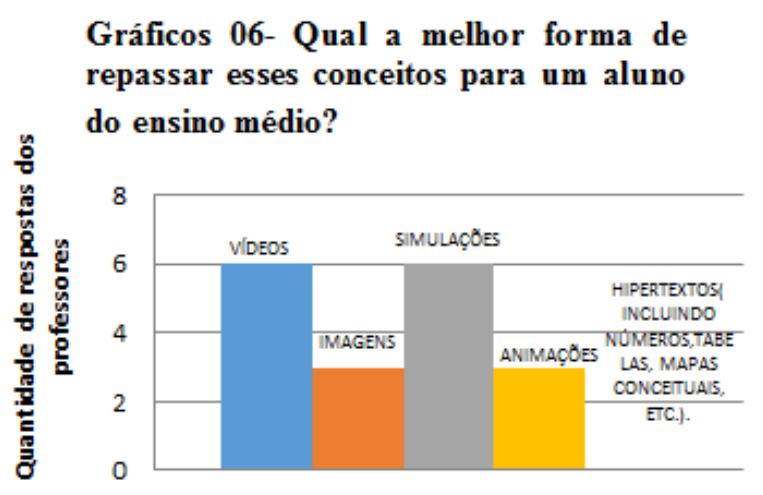

Fonte: Pesquisa de campo.

Nessa pergunta os professores marcaram mais de uma alternativa, pois muitos apontam que um número maior de objetos de aprendizagem torna a aprendizagem mais significativa. Destas respostas 33,3\% foram destinadas para vídeos, $16,7 \%$ apontaram imagens, $33,3 \%$ simulações, $16,7 \%$ animações e $0 \%$ para hipertextos (incluindo números, tabelas, mapas conceituais, etc.).

Os tipos de OA's mais indicados pelos professores foram as simulações computacionais e os vídeos. Essa relação talvez seja devido à possibilidade destes fornecerem com clareza bem significativa alguns conceitos trabalhados em sala, além de apresentarem um acervo considerável e de fácil manipulação. Já os hipertextos não apresentaram nenhum percentual, este resultado talvez esteja ligado à necessidade de eles precisarem de um tempo maior de preparação e não serem ferramentas tão atrativas, capazes de prender a atenção do aluno por um longo período.

A última pergunta foi de cunho subjetivo consistindo numa abordagem ao professor, indagando-o: você considera importante abordar estes conceitos atuais de nanociência por meio de objetos de aprendizagem? Percebemos um padrão na resposta dos professores, todos apontaram que a nanociência é um tema importante e bastante interessante para trabalhar em sala de aula, mas por apresentar alguns conceitos com maior dificuldade de compreensão os objetos de aprendizagem irão de encontro a essas dificuldades, com o objetivo de saná-las da melhor forma possível. Acreditamos que esse percentual seja devido à consciência que os professores têm sobre a importância dos temas modernos, nanociência, e o uso da tecnologia em sala de aula, objetos de aprendizagem. Diversas foram as respostas dos professores, entre elas podemos citar:

\footnotetext{
É de grande importância essa abordagem no âmbito escolar, levando em consideração a necessidade dos educandos de estarem a par de conhecimentos que poderão ser úteis futuramente, nas diversas aplicações que poderão ser feitas. E os objetos de aprendizagem são hoje ferramentas importantes na transmissão de conhecimentos e na interação com o mesmo.
}

A pesquisa mostrou que muitos professores já apresentam algum conhecimento prévio de nanociência. Além disso, por meio das respostas é possível verificar que eles acreditam ser importante trabalhar este tema no ensino médio considerando a contribuição dos objetos de aprendizagem expostos ao longo deste trabalho. Os professores que responderam aos questionários tiveram acesso aos OA's expostos aqui, tais como animação, vídeo, simulação e imagem dentro do contexto do estudo da nanociência e eles foram unânimes em afirmar que estas ferramentas podem sim ser inseridas dentro do contexto das salas de aula. 
OBJETOS DE APRENDIZAGEM APLICADOS AO ENSINO DA NANOCIÊNCIA

\section{CONSIDERAÇÕES FINAIS}

A partir dos dados coletados por meio da pesquisa realizada é possível constatar que os professores podem utilizar os OA's na realização de aulas expositivas, incentivando o aluno a pesquisar, recorrendo a esses recursos em sua casa ou até mesmo no laboratório de informática da escola, já que estas entidades tecnológicas são distribuídas pela internet e de fácil acessibilidade.

Com esse trabalho foi possível identificar algumas facilidades e complicações na utilização dos OA's na prática docente. Conseguimos um esclarecimento eficaz dos conceitos de nanociência por meio dos objetos de aprendizagem distribuídos pela internet. Houve uma pequena dificuldade para encontrar alguns dos OA's expostos ao longo deste trabalho, pois a nanociência proposta para o âmbito escolar ainda não é muito difundida. Entre os instrumentos que apresentaram um acervo maior temos: os vídeos e imagens, sendo estes de fácil acessibilidade e manipulação, apresentando um esclarecimento bem eficaz dos conceitos. Através dessa pesquisa ficou nítido o quão vasto é a aplicabilidade da nanociência, apresentando um campo de atuação muito grande, com fins de melhoramento da maneira como vivemos.

Diante dos resultados da pesquisa nas escolas ficou claro que muitos professores têm conhecimento de nanociência, mas muitos não mostram estes conceitos na sala de aula, porém consideram importante que os alunos obtenham tais informações, mesmo que de forma rápida.

É importante que as escolas abranjam mais sobre assuntos atuais como a nanociência, mostrando pesquisas modernas e propondo métodos de ensino alternativos. Além de inserir os alunos em um contexto atual, esta abordagem estimula o processo de ensino/aprendizagem levando os alunos a experimentar momentos lúdicos e o professor a ter o prazer e a alegria de observar os alunos na ânsia por mais conhecimento, este por sua vez passado de forma prazerosa e significativa.

\section{REFERÊNCIAS}

ALVES, O. L. Nanotecnologia, nanociência e nanomateriais: quando a distância entre presente e futuro não é apenas questão de tempo. Parcerias estratégicas, v. 9, n. 18, p. 23-40, 2010.

AMARAL, L. H.; SANTOS, M. E. K. L. d. Avaliação de objetos virtuais de aprendizagem no ensino de matemática. Revista de Ensino de Ciências e Matemática, v. 3, n. 2, p. 83-93, 2012.
ANDRADE, N. F.; AGUIAR, A.; KIM, Y.; ENDO, M.; FREIRE, P.; BRUNETTO, G.; GALVAO, D.; DRESSELHAUS, M.; FILHO, A. S. Linear carbon chains under high pressure conditions. Journal of Physical Chemistry. C. (Online), v. 1, 2015.

AUDINO, D. F.; NASCIMENTO, R. S. Objetos de aprendizagem - diálogos entre conceitos e uma nova proposição aplicada à educação. Revista Contemporânea da Educação, v. 5, n. 10, p. 128-148, 2010.

BRASIL. Ministério da Educação. Parâmetros curriculares nacionais: Ensino Médio, parte III. Brasília: Secretaria de Educação Fundamental, MEC/SEB, 2000.

CETENE. Microscópio eletrônico de transmissão (MET). Disponível em: <http://www.cetene.gov.br/ pdf/met.pdf>. Acesso em: 03 mai. 2016.

ELLWANGER, F. A. L.; FRANCISCANO, J. R.; FRANCISCANO, M. G.; FRANCISCANO, V. B.; FRANCISCANO, S. B. F. O ensino de nanociências por meio de objetos de aprendizagem. Revista Novas Tecnologias na Educação, v. 10, n. 1, p. 1-10, 2012.

FAPESP. Apareceu o Mickey. 2010. Disponível em: <http://revistapesquisa.fapesp.br/2010/02/04/ apareceu-o-mickey/> Acesso em: 24 abr. 2015.

FERREIRA, H. S.; RANGEL, M. C. Nanotecnologia: aspectos gerais e potencial de aplicação em catálise. Química Nova, São Paulo, v. 32, n. 7, p. 1860-1870, 2009.

FEYNMAN, R. P. Há mais espaços lá embaixo. Revista Parcerias Estratégicas, Brasília, n. 18, p. 137-155, 2004.

FLÔRES, M. L. P.; TAROUCO, L. M. R. Diferentes tipos de objetos para dar suporte a aprendizagem. RENOTE, v. 6, n. 2, 2008.

GERHARDET, T. E.; SILVEIRA, D. T. Métodos de pesquisa. 1. ed. Porto Alegre: Editora da UFRGS, 2009.

HEALY, N. Why nano education? Journal of Nano Education, v. 1, p. 6-7, 2009.

HOLTZ, R. D.; OSWALDO, L. A. Nano mickey - silvernanoparticle. 2010. Disponível em: <https://www.youtube.com/watch?v=rIkNotUAuNQ> Acesso em: 23 abr. 2015. 
INVERNIZZI, N. Visões de futuro: nanociência e nanotecnologia no jornal da ciência. VII Jornadas

Latinoamericanas de Estudios Sociales de la Ciencia y Tecnología: Rio de Janeiro, 2008.

MACHADO, D. I.; NARDI, R. Construção de conceitos de física moderna e sobre a natureza da ciência com o suporte da hipermídia. Revista Brasileira de Ensino de Física, v. 28, n. 4, p. 473-485, 2006.

PELIZZARI, A.; KRIEGL, M. d. L.; BARON, M. P.; FINCK, N. T. L.; DOROCINSKI, S. I. Teoria da aprendizagem significativa segundo ausubel. Curitiba: Revista PEC, v. 2, n. 1, p. 37-42, 2002.

SÁ, L. V. d.; ALMEIDA, J. V. d.; EICHLER, M. L. Classificação de objetos de aprendizagem: uma análise de repositórios brasileiros. $X V$ Encontro Nacional de Ensino de Química (XV ENEQ), Brasília, DF, Brasil, 2010.

SALES, G. L.; LEITE, E. A. M.; VASCONCELOS, F. H. L. Tdic como suporte à aprendizagem de física no ensino médio. XXI Simpósio Nacional de Ensino de Física-SNEF, 2015.

SALES, G. L.; VASCONCELOS, F. H. L.; FILHO, J. A. de C.; PEQUENO, M. C. Atividades de modelagem exploratória aplicada ao ensino de física moderna com a utilização do objeto de aprendizagem pato quântico. Revista Brasileira de Ensino de Física, v. 30, n. 3, p. 3501, 2008.

SILVA, C. B.; BARBOZA, F. M. A importância de atividades lúdicas para a complementação do aprendizado dos alunos. Revista Iniciação e Formação Docente, v. 1, n. 2, 2014.

Questionários avaliativos: uma proposta metodológica para o ensino de física. XXI Simpósio Nacional de Ensino de Física - SNEF, 2015.

TVUFPR. Entrevista do Prof. Aldo J. G. Zarbin à TV-UFPR. 2012. Disponível em: <http://nanocarbono. ufmg.br/elgg/pg/videos/play/sampaio/2435/ scientia-nanotecnologia-entrevista-do-prof-aldo-j-g-zarbin $>$ Acesso em: 24 abr. 2015.

UNIFRA. Mais Unifra. Espaço Virtual de Aprendizagem. Santa Maria, RS, 2011. Disponível em: <http://maisunifra.com.br/> Acesso em: 29 mar. 2015. 